\title{
VIDEO ANIMASI MESIN OFFSET SEBAGAI MEDIA PEMBELAJARAN CETAK OFFSET
}

\author{
Toriqu Ahira Rohmana, Saida Ulfa, Eka Pramono Adi \\ Teknologi Pendidikan, Fakultas Ilmu Pendidikan, Universitas Negeri Malang. \\ Jl. Semarang No.5, Malang, 65145, Indonesia. \\ Toriquahira@gmail.com
}

\author{
Article History \\ Received: 15 Maret 2021, Accepted: 07 April 2021, Published: 20 Februari 2022
}

\begin{abstract}
Abstrak
Video animasi mesin offset adalah sebuah produk berupa video pembelajaran yang memudahkan dan meningkatkan motivasi belajar siswa. Research and Development (R\&D) atau penelitian dan pengembangan merupakan metode penelitian yang digunakan untuk menghasilkan produk. Metode yang digunakan mengacu pada model Sadiman. Media pembelajaran yang dikembangkan memuat mata pelajaran Cetak Offset materi Transportasi Kertas pada Mesin Offset. Produk ini dikembangkan untuk siswa Produksi Grafika yang layak diterapkan didalam proses pembelajaran dan berposisi menjadi pelengkap, yang berarti dirancang dan ditujukan melengkapi materi yang akan disampaikan dalam proses pembelajaran. Kelayakan produk ini telah diuji oleh ahli media adalah seorang dosen Teknologi Pendidikan dan ahli materi seorang guru pengajar matapelajaran produktif berpengalaman mengajar lebih dari 10 tahun dan mendapati kriteria layak. Produk juga telah diujicobakan kepada siswa jurusan Produksi Grafika dan penelitian mendapatkan tanggapan mayoritas positif. Sehingga dapat disimpulkan bahwa video animasi memiliki keistimewaan yaitu memudahkan siswa, menambah kemenarikan siswa, serta menambah motivasi siswa dalam aktifitas belajar siswa dengan ini dinyatakan layak digunakan.
\end{abstract}

Kata kunci: Animasi; Media Pembelajaran; Mesin; Cetak Offset

\begin{abstract}
The offset machine animation video is a product in the form of a learning video that facilitates and increases student motivation. Research and Development $(R \& D)$ or research and development is a research method used to produce products. The method used refers to Sadiman's model. The learning media developed contains Offset Printing subjects, Paper Transportation material on an Offset Machine. This product was developed for students of Graphic Production which is feasible to be applied in the learning process and has a complementary position, which means that it is designed and aimed at complementing the material to be conveyed in the learning process. The feasibility of this product has been tested by media experts, namely an Educational Technology lecturer and material expert, a productive subject teaching teacher with more than 10 years of experience in teaching and has found feasible criteria. The product has also been tested on students majoring in Graphic Production and the research has received a majority of positive responses. So it can be concluded that the animated video has the privilege of making it easier for students, increasing student attractiveness, and increasing student motivation in student learning activities hereby declared fit for use.
\end{abstract}

Keyword: Animation; Learning Media; Machine; Lithography 


\section{PENDAHULUAN}

Pada era sekarang ini, siswa dituntut untuk menemukan kemampuan serta kapasitas diri secara mandiri, dan guru berperan sebagai fasilitator untuk membimbing dan mengarahkan siswa menemukan dan mengembangkan kemampuan yang dimiliki secara maksimal. Namun faktanya, dalam mengembangkan potensi yang dimiliki, siswa masih belum bisa sepenuhnya mandiri, mereka lebih ketergantungan kepada guru dalam menggali kemampuan dirinya.Berdasarkan hasil dari wawancara dan observasi di SMK Negeri 4 Malang bahwasanya metode dalam proses mengajar masih menggunakan metode ceramah, tidak ada media pembelajaran yang sesuai dengan karakteristik siswa, alokasi waktu belajar relatif sedikit. Penggunaan media dan metode yang kurang meskipun sudah didukung dengan adanya mesin secara asli, namun akibat kurangnya waktu jam pelajaran, maka berimbas pada kurangnya pemahaman siswa terhadap materi yang disampaikan oleh guru, siswa cenderung pasif dan kurangnya ketertarikan siswa dalam belajar.

Di Indonesia bahkan di dunia, ilmu grafika masih menjadi ilmu unik yang cukup tidak dikenal oleh khalayak umum. Masyarakat hanya menggunakan hasil dari produk grafika saja,tanpa mengetahui bagaimana proses pembuatannya (Satriesna, 2016). Hal ini dibuktikan dengan kurangnya penelitian yang mengangkat materi tentang Ilmu grafika,lebih spesifiknya cetak offset. Ilmu grafika dalam hal ini meliputi pra-cetak, cetak, dan finishing. Disebut pra-cetak dikarenakan prosis ini dilalui sebelum masuk kedalam proses cetak didalam pracetak antara lain adalah desain, lay-out atau pewajahan foto reproduksi dan seterusnya.Sebagai mana pra cetak, untuk cetak juga banyak memiliki jenis mulai dari cetak saring (sablon), cetak tinggi, flexografi, dan juga cetak offset. Terakhir hal ini adalah finishing atau penyelesaian. Beberapa keilmuan tersebut jika tidak banyak yang tahu akan berakibat pada kurangnya sumber daya manusia yang menguasai dan berkompeten dalam bidang atau keilmuan ini, sejalan dengan penelitian yang dilakukan oleh (Yuhadiman, 2014) mengatakan bahwa masih sangat kurang sumber daya manusia yang ahli dibidang grafika ini. Diharapkan dengan adanya media ini, dapat mengatasi perasalahan yang ada, sehingga pembelajaran dapat tercapai adanya, serta bertambahnya sumberdaya manusia yang berkompeten didalam bidang kegrafikaan.

Masalah yang didapati yaitu keterbatasan media pembelajaran juga banyak ditemukan dalam penelitian sebelumnya seperti (Tarchi et al., 2021) menyuarakan keprihatinan tentang keefektifan belajar melalui teks konten yang setara. (Lin \& Li, 2018) Peserta didik mengalami kesulitan belajar tanpa adanya media pembelajaran.(Lee et al., 2020) Masyarakat kurang mendalami pemahaman materi yang disampaikan oleh tutor. (González \& Skultety, 2018) Perlu sebuah kolaborasi media agar kekayaan akal siswa menjadi utuh. Serta termuat juga dalam penelitian yang dilaksanakan oleh (Tu et al., 2018) kurangnya pemahaman, kepartisipasian siswa tanpa adanya media pembelajaran yang sesuai.

Fitriani et al., (2020) dalam peneletiannya berpendapat bahwa penggunaan video animasi memiliki tingkat keberhasilan sebesar 92,5\%. Dalam penelitian (Luhulima et al., 2018) tentang penggunaan video pembelajaran karakter berbasis animasi ,hasil yang didapat yaitu setiap anak memiliki nilai kognitif berdasarkan hasil tes lisan yang baik untuk setiap meteri yang diajarkan, dan menunjukan sikap yang baik pada saat melaksanakan aktifitas - aktifitas yang diberikan. Dibuktikan juga oleh (HALILI et al., 2011) Sebanyak 62\% siswa setuju bahwa video pembelajaran membantu meningkatkan prestasi yang diharapkan dalam pembelajaran. Menurut (Fauziyah et al., 2020) video dengan pengayaan tokoh dan animasi mampu meningkatkan kemampuan pemahaman konseptual siswa. Berdasarkan penjelasan diatas, maka diperlukan suatu media dalam aktifitas belajar demi tercapainya tujuan pembelajaran. Masalah diatas dapat ditangani dengan pemanfaatan video animasi pembelajaran. 
Dari beberapa jenis video pembelajaran yang ada, salah satu media yang dikemas seperti halnya video animasi. Menurut (Widiyasanti \& Ayriza, 2018) dalam artikelnya, video animasi akan sangat berguna sebagai media pembelajaran alternatif dan membawa manfaat dalam proses pembelajaran. Dalam artikel Imamah___(2012) tentang pengaruh pemanfaatan video animasi didalam kelas, bahwa pemanfaatan dan penggunaan video animasi dalam aktifitas belajar mengajar dapat memperbaiki hasil belajar siswa didalam kelas. Penelitian oleh Apriliyani._(2020) memaparkan bahwa video animasi dalam pembelajaran memberikan dampak positif motivasi siswa. Maka video animasi pembelajaran mulai dimanfaatkan sebagai media dalam proses aktifitas belajar. Selain itu, menurut (Surahman \& Surjono, 2017) dalam penelitianya berpendapat, media dalam aktifitas belajar mengajar dapat menambah motivasi belajar siswa. Menurut (Muhammad, 2017) motivasi diartikan sebagai keingan untuk mencurahkan segala tenaga untuk mencapai tujuan yang diinginkan. Sedangkan menurut (Hamdu \& Agustina, 2011) motivasi adalah salah satu hal yang berpengaruh pada kesuksesan aktifitas belajar siswa. Maka, motivasi secara sederahananya adalah suatu hal yang mempengarui dan dicurahkan sekuat tenaga demi suksesnya aktifitas belajar atau tujuan yang diinginkannya.

Dari penjabaran diatas, video animasi dapat menjadi media dalam aktifitas belajar mengajar dapat mempermudah guru menyampaikan materi ataupun mempermudah siswa menerima materi dan memotivasi siswa. Produk dirancang, dikembangkan dan dikemas seefektif mungkin, serta tidak menyebabkan siswa bosan. sehingga siswa termotivasi dalam belajar. Video animasi dimanfaatkan sebagai media belajar yang bersifat komplemen, Dengan demikian, langkah yang tepat dilakukan adalah mengembangkan produk berupa video animasi mesin offset sebagai media pembelajaran cetak offset ditujukan untuk siswa kelas X jurusan Produksi Grafika yang layak digunakan dalam pembelajaran, meningkatkan motivasi belajar siswa. Produk ini dikembangkan untuk siswa kelas $\mathrm{X}$ guna mengatasi permasalahan yang ada, sehingga pesan atau materi yang disampaikan dapat terserap oleh siswa.

\section{METODE}

Penelitian ini merupakan penelitian dan pengembangan. Model pengembangan yang digunakan pada penelitian dan pengembangan ini mengacu pada penggunaan model pengembangan Sadiman (2011). Alasan pemilihan model tersebut adalah model Sadiman merupakan model yang digunakan untuk produk atau media yang mengimplementasikan berdasar pada naskah dalam menciptakan desain media yang akan diterapkan sebagai dasar produksi media. Penggunaan model Sadiman juga dilakukan pada penelitian (Febrianto et al., 2020).

Dalam pengembangan video animasi mesin offset sebagai media pembelajaran cetak offset tentang transportasi kertas kelas X SMK Jurusan Produksi Grafika disesuaikan dengan kebutuhan berdasarkan latar belakang masalah, agar tingkat kelayakan dapat diketahui maka uji coba dilaksanakan kepada ahli media, adalah dosen jurusan Teknologi Pendidikan Universitas Negeri Malang, ahli materi merupakan tenaga pengajar mata pelajaran produktif grafika di SMK Negeri 4 Malang, dan siswa, guna mengetahui sudut pandang user atau pengguna, responden adalah siswa jurusan Produksi Grafika di SMK Negeri 4 Malang berjumlah 3 orang siswa. Data yang dihasilkan dalam pembuatan video animasi ini adalah membagikan angket berisi pernyataan dan kolom komentar serta saran untuk menguji tingkat kelayakan media oleh ahli media, angket juga diberikan kepada ahli materi, dan juga siswa. 


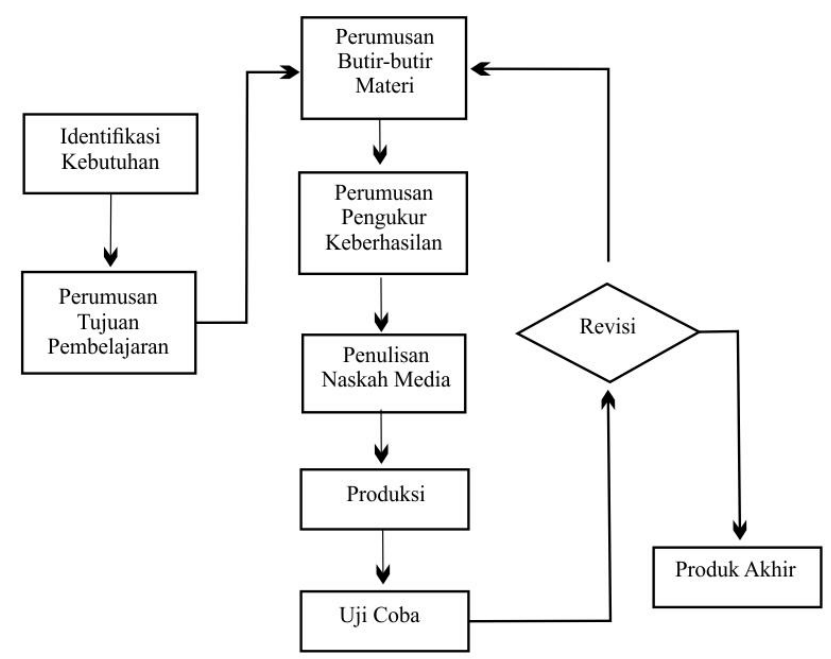

Gambar 1. Prosedur pengembangan Sadiman (2011)

Penelitian ini hanya sampai uji kelayakan kepada ahli media, materi dan juga pengguna (siswa). Teknik Analisis data ahli media, ahli materi dan siswa berdasarkan skor angket yang dihasilkan, tanggapan/komentar dari para narasumber telah di reduksi. Dengan demikian data yang telah direduksi akan memberikan gambaran yang lebih jelas sehingga dapat ditarik kesimpulan kelayakan media. Dalam hal ini spesifikasi para ahli diperlukan guna keabsahan data yang dihasilkan, spesifikasi ahli media diantara lain adalah dosen Teknologi Pendidikan Universitas Negeri Malang, beriwayat mengajar video pembelajaran. Untuk ahli materi yaitu seorang pengajar mata pelajaran produktif grafika berpengalaman mengajar lebih dari 20 tahun. Sedangkan untuk responden user dipilihlah 3 orang siswa SMK Negeri 4 Malang jurusan produksi grafika.

Dalam angket yang didistibusikan, kepada ahli media memuat diantaranya aspek fungsi dan manfaat, aspek visual media, aspek audio media, aspek tipografi, aspek bahasa, serta aspek pemrogaman media. Keenam aspek tersebut dibagi menjadi 12 indikator penilaian. Angket untuk ahli materi berisi pernyataan didasari aspek kesesuaian materi, aspek keakuratan materi, aspek kemutakhiran dan keruntutan materi. Sedangkan angket untuk user media berisi diantara lain yaitu aspek kemudahan, aspek kemenarikan, aspek memotivasi. Dalam masing-masing angket yang di ajukan kepada masing-masing responden sehingga video animasi mesin offset sebagai media pembelajaran yang dikembangkan dapat dikatakan layak dan dapat digunakan dalam pembelajaran jika respon dari ahli media, ahli materi, maupun pengguna mendapati respon yang positif.

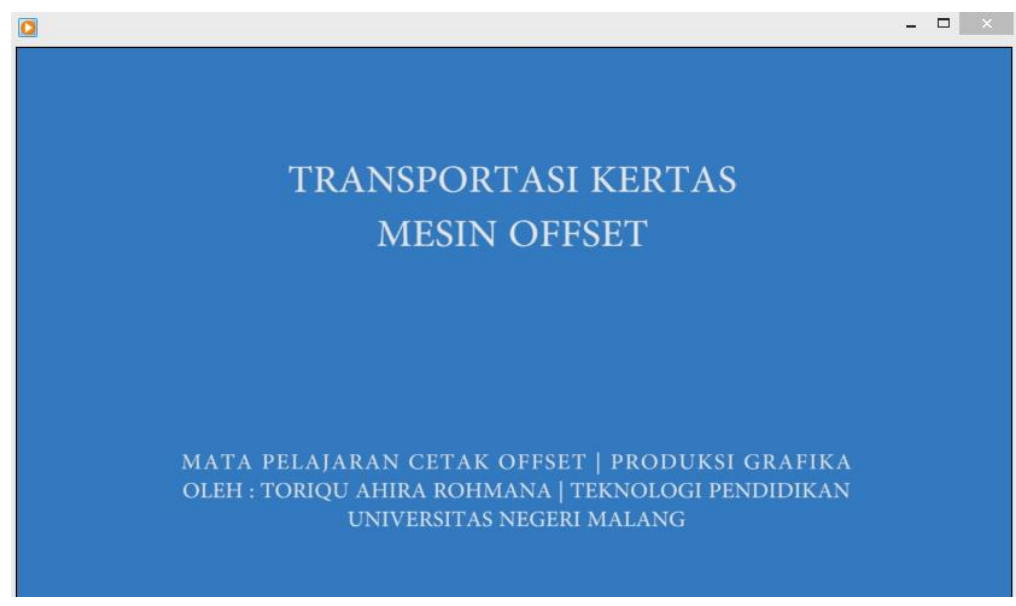

Gambar 2. Tampilan Video animasi mesin offset 


\section{HASIL}

Dari penelitian dan pengembangan ini, telah menghasilkan produk berupa video animasi mesin offset dengan tampilan pada gambar 2 dan 3.

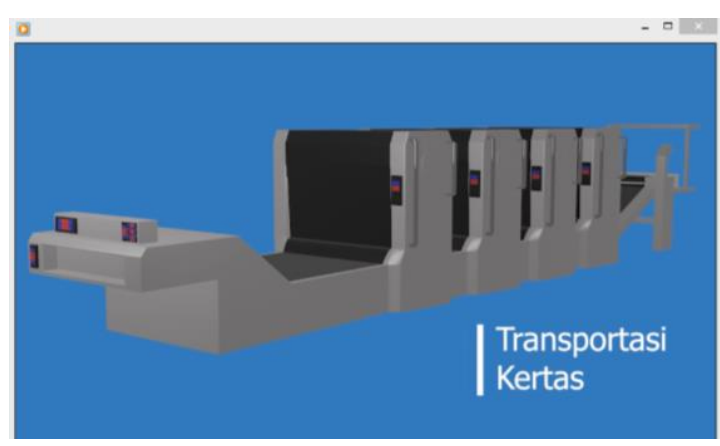

Gambar 3. Tampilan Video animasi mesin offset

Berdasarkan hasil ujicoba media oleh ahli media, ahli materi dan uji coba kepada siswa tentang video animasi diatas, diperoleh hasil pada tabel 1 .

Tabel 1. Tanggapan Ahli Media

\begin{tabular}{ccccc}
\hline Subjek & Mean & Median & Modus & Persentase \\
\hline Ahli Media & 3,83 & 4 & 4 & $95,8 \%$ \\
\hline
\end{tabular}

Berdasarkan angket respon ahli media pada tabel 1, dari hasil data yang didapatkan, didapati Mean 3,83 Median 4 serta Modus 4. Berdasarkan perhitungan tanggapan positif yang diberikan oleh ahli media, dapat diperoleh persentase sebesar 95,8\%. Ahli media juga memberikan saran dan komentar terhadap media yang dikembangkan, dan video animasi mesin offset yang dikembangkan dinyatakan layak oleh ahli media.

Tabel 2. Tanggapan oleh Ahli Materi

\begin{tabular}{ccccc}
\hline Subjek & Mean & Median & Modus & Persentase \\
\hline Ahli Materi & 3,40 & 3 & 3 & $85 \%$ \\
\hline
\end{tabular}

Berdasarkan angket respon ahli materi pada tabel 2, dari hasil data yang didapatkan, didapati Mean 3,40 Median 3 serta Modus 3. Berdasarkan perhitungan tanggapan positif yang diberikan oleh ahli media, dapat diperoleh persentase sebesar $85 \%$. Ahli materi juga memberikan saran dan komentar terhadap media yang dikembangkan, dan video animasi mesin offset yang dikembangkan dinyatakan layak oleh ahli materi.

Tabel 3. Respon Siswa

\begin{tabular}{ccccc}
\hline Subjek & Mean & Median & Modus & Persentase \\
\hline 3 Siswa & 3,40 & 4 & 4 & $91,6 \%$ \\
\hline
\end{tabular}

Dan selanjutnya produk diujicobakan kepada siswa, guna mengetahui sudut pandang penggunaan produk yang dikembangkan, berdasarkan paparan pada tabel 3, dari hasil data yang didapatkan, didapati Mean 3,66 Median 4 serta Modus 4. Berdasarkan perhitungan tanggapan positif yang diberikan oleh ahli media, dapat diperoleh persentase keseluruan sebesar 91,6\%. Sejalan dengan analisis data yang telah dilaksanakan, maka dapat disimpulkan bahwa media yang dikembangkan berupa video animasi mesin offset sebagai media pembelajaran cetak offset dinyatakan layak digunakan dalam proses pembelajaran.

\section{PEMBAHASAN}

Video animasi mesin offset menjadi sebuah produk berupa media pembelajaran video berbasis animasi untuk mempermudah siswa dalam memahami materi transportasi kertas. Menurut Setyosari dan Sihkabuden (2005), media audio-visual yaitu media yang dapat menghasilkan rupa dan suara dalam satu media. Misalnya film bersuara dan televisi.Video membantu guru dalam 
penyampaian materi dan menciptakan situasi belajar yang tidak monoton sehingga siswa mudah memahami materi (Kurniawan et al., 2018). Video dapat membantu menambah ketelitian dan memperbaiki kualitas belajar dalam sebuah lingkup pembelajaran (Massey et al., 2017). Juga terbukti dalam penelitian (Montero Perez, 2020) pasca menonoton sebuah tayangan video setiap pemirsa akan menyerap kosakata dan pemahaman baru. Sama halnya dengan penjelasan diatas, media pembelajaran terutama berbasis video, mempunyai keistimewaan baik membantu pembelajaran seperti menciptakan situasi kondisi belajar yang tunggal warna menjadi pancawarna, menambah ketelitian dan kualitas pembelajaran dan juga penyerapan kosakata bahkan sesuatu hal yang dianggap baru. Pembaharuan ini diperlukan untuk mengimbangi setiap langkah perkembangan teknologi disetiap hari bahkan setiap detik.

Dalam pemilihan media, guru dituntut harus lebih kreatif dan juga memikirkan kestabilan suasana belajar. Disamping itu, dalam pemilihan media harus selaras dengan materi atau pesan yang akan disampaikan. Dalam penelitihan ini dihasilkan sesuai dengan kebutuhan serta masalah yang telah diperinci pada pendahuluan, yaitu vide animasi mesin offset untuk siswa SMK Negeri 4 Malang berjurusan Produksi Grafika dengan materi transportasi kertas. Animasi komputer dan fisik adalah salah satu cara untuk merubah suasana hati (Esendemir, 2014). Juga menurut (Efendi et al., 2020) Perkembangan teknologi , animasi berkembang sehingga dapat memberikan penjelasan mengenai sebuah konsep pembelajaran disertai grafis, teks, dan warna. Sehingga hal yang berpengaruh didalam animasi untuk keberhasilan penjelasan konsep pembelajaran adalah grafis yang menarik sebagai penyokong unsur kemenarikan, teks yang jelas serta mudah untuk dibaca sebagai penunjang unsur kemudahan, dan kecocokan warna sebagai daya tarik tersendiri untuk siswa, sehingga siswa dapat termotivasi akan hal itu.

Media bermanfaat sebagai fasilitas relasi antara guru dengan siswa di dalam aktivitas belajar (Luppy et al., 2020). Sedangkan (Fahyuni \& Istikomah, 2016) berpendapat bahwa media pembelajaran ialah segenap hal yang berkaitan dengan benda dan sistem yang dirancang untuk interaksi guru dalam menyampaikan pesan kepada murid dengan tujuan supaya informasi dapat diterima murid didalam aktivitas belajaran dengan baik. Berpendapat juga (Manolev et al., 2019) dalam penelitiannya bahwa media berperan penting dalam praktek pendisiplinan dan pemahaman ilmu. Juga menurut (Haythornthwaite et al., 2018) materi yang mudah dipahami dan dimengerti, memiliki ketrampilan dalam menggunakan media pembelajaran merupakan asas penting demi ketercapaiannya tujuan belajar.

Peranan media pembelajaran menurut Hidayat (2010) Manfaat secara global, memperlancar korelasi antara guru dengan siswa adapun kegiatan pembelajaran akan menjadi lebih ringkas, padat dan efisien. Secara sederhana media berperan dan bermanfaat penting dalam setiap konsep pembelajaran yang akan dilaksanakan oleh murid atau siswa. Sehubungan dengan ini maka peran media sangatlah penting adanya, tanpa adanya media pesan atau materi tidak akan tersampaikan dengan baik. Maka daripada itu, riset ini menawarkan solusi akan pentingnya media pembelajaran yang sesuai dengan kebutuhan siswa dalam pemahaman materi dan disiplin ilmu. Kelancaran hubungan antara tenaga didik dengan siswa ini diperlukan guna memperkaya pemahaman dan keikutsertaan siswa didalam suatu proses keberagaman pembelajaran.

Cetak Offset dalam prakteknya, mempunyai beberapa unit mesin, yaitu unit pemasukan, unit pembasahan, unit penintaan, unit penyetakkan, unit pengeluaran. Kunci dari hasil penyetakan yang berkualitas adalah terletak pada bagian unit pembasahan dan mutlak adanya (Aydemir \& Yenidoğan, 2019). Pengontrolan unit pembasahan dilakukan agar setiap grafis yang tercetak mendapati cukup tone warna yang pekat, sehingga bisa menghasilkan cetakan yang baik dan bagus. Skill menjalankan mesin offset ini jarang orang bisa melakuinya apalagi yang bisa 
segalanya, sedangkan hasil dari produk cetak offset setiap masa kita bisa menikmatinya, hal ini harus kita ketahui, karena untuk membangun sumber daya manusia yang memumpuni, terutama di dunia percetakan maka haruslah ada penyokong keilmuan yang setimpal dengan hal ini. Setiap pembuatan media cetak dan properti iklan juga diperlukan sebuah teknik percetakan atau ilu kegrafikaan. Peranan dunia percetakan atau ilmu kegrafikaan dalam pendidikan cukup andil adanya.

Video Animasi Mesin Offset materi Transportasi Kertas pada mesin offset dikembangkan sebagai media pembelajaran sesuai dengan kebutuhan dilapangan, dikembangkan melalui beberapa tahapan-tahapan yang mengacu dalam metode pengembangan model sadiman. Dimanfaatkan sebagai media untuk membantu dalam penyampaian pesan (materi) oleh guru kepada siswa. Media pembelajaran yang dikembangkan ini bersifat sebagai komplemen atau pelengkap didalam aktifitas belajar siswa. Media sebagai komplemen menurut (Zhang \& Pan, 2019) media berjalan beriringan dengan tutor atau pengajar, 2 hal ini tiada dapat dipisahkan antara satu dengan yang lainnya. Sedangkan menurut (Erolin et al., 2019) komplemen dapat diartikan sebagai pelengkap sarana belajar antara pengajar dan siswa dalam suatu aktifitas belajar, kelas maupun luaran kelas.

Media yang dikembangkan yaitu video animasi mesin offset sebagai media pembelajaran cetak offset, materi transportasi kertas berisi 5 pokok materi, diantaranya yaitu unit pemasukkan, unit pembasahan, unti penintaan, unit penyetakkan, unit pengeluaran. Media dapat diakses secara mudah melalui dekstop, laptop maupun gawai siswa, dengan catatan perangkat tersebut tersambung dengan koneksi internet. Hal ini termasuk kelebihan yang dimiliki oleh produk ini, dengan adanya fitur ini, siswa atau pengguna diharapkan dapat mengakses video animasi dimana dan kapan saja. Hal ini termasuk dalam aspek kemudahan dalam penggunaan, seperti halnya menurut (Al-Rahmi et al., 2018)dalam risetnya, kesanggupan pengguna dalam mengakses fitur yang disajikan ialah maksud dari unsur kemudahan. Kemudahan ini sangatlah diperlukan adanya, guna dapat dipahaminya sebuah materi yang disajikan dalam proses belajar mengajar.

Selain dari adanya unsur kemudahan, tak luput juga video animasi mesin offset ini juga mempunyai keistimewaan dalam unsur kemenarikan, yakni terdapatnya suara announcer yang sedap didengar, tampilan yang menarik serta animasi yang mudah dipahami dalam setiap geraknya. Unsur kemenarikan ini termaktub juga didalam penelitian oleh (Iftene \& Trandabăt, 2018) berpendapat bahwa kemenarikan media diperlukan agar kebosanan dalam aktifitas belajar dapat diatasi, serta membuat mood pebelajar menjadi positif. Setelah itu terdapat juga unsur memotivasi siswa, hal yang membuat siswa semangat atau termotivasi untuk menerima materi yang disuguhkan. Sebuah keistimewaan juga dihadirkan yaitu media dapat diakses dengan mudah oleh pihak pengguna, dapat diakses melalui gawai siswa, laptop siswa, komputer siswa, asalkan terhubung dalam jaringan internet. Hal ini pula menjadi faktor penting dalam kelebihan dalam penggunaan sebuah media, mengingat juga siswa pada zaman sekarang sudah pandai mengoperasikan sebuah ponsel pintar.

\section{SIMPULAN}

Berdasar pada hasil uji kelayakan, oleh ahli media, video animasi mesin offset mendapatkan kriteria layak digunakan dalam pembelajaran. Sedangkan, oleh ahli materi, video animasi mesin offset mendapatkan kriteria layak digunakan dalam pembelajaran. Ujicoba kepada 3 orang siswa jurusan produksi grafika di SMK Negeri 4 Malang. Hasil ujicoba ini mendapatkan respon positif sebesar 91,6\% dengan Mean 3,40 Median 3 serta Modus 3. Sehingga dapat disimpulkan dan dikriteriakan layak digunakan didalam pembelajaran. Dalam Video Animasi Mesin Offset juga mempunyai beberapa keistimewaan, contohnya untuk meningkatkan kemudahan siswa, 
meningkatkan kemenarikan siswa serta menambah motivasi belajar siswa. Para responden beranggapan video animasi mesin offset ini berharga untuk pembelajaran siswa, baik secara kualitatif maupun kuantitatif. Penelitian ini dibatasi oleh jumlah sampel modul yang kecil dan jumlah peserta yang sedikit. Selanjutnya, analisis yang lebih rinci dengan pengukuran lebih lanjut, termasuk efikasi diri dan kepercayaan diri, akan menghasilkan kesimpulan yang lebih komprehensif. Namun, sejauh ini video animasi mesin offset menyediakan alat bantu yang efektif dan mudah diakses untuk memperoleh keterampilan dan pemahaman sesuai dengan kompetensi, untuk pelajar berjurusan produksi grafika

\section{DAFTAR RUJUKAN}

Al-Rahmi, W. M., Alias, N., Othman, M. S., Marin, V. I., \& Tur, G. (2018). A model of factors affecting learning performance through the use of social media in Malaysian higher education. Computers \& Education, 121, 59-72.

Apriliyani, F. (2020). Identifikasi Motivasi Siswa Sekolah Dasar Menggunakan Video Animasi Tentang Sumber Daya Alam. Integrated Science Education Journal, 1(1), 23-29.

Aydemir, C., \& Yenidoğan, S. (2019). The influence of surface tension on wetting in dampening solution and sustainability of printing: A review. J Graph Eng Des, 10(1), 5-11.

Efendi, Y. A., Adi, E. P., \& Sulthoni, S. (2020). Pengembangan Media Video Animasi Motion Graphics pada Mata Pelajaran IPA di SDN Pandanrejo 1 Kabupaten Malang. JINOTEP (Jurnal Inovasi Dan Teknologi Pembelajaran): Kajian Dan Riset Dalam Teknologi Pembelajaran, 6(2), 97-102.

Erolin, C., Reid, L., \& McDougall, S. (2019). Using virtual reality to complement and enhance anatomy education. Journal of Visual Communication in Medicine, 42(3), 93-101.

Esendemir, G. (2014). Effect of physical modeling and computer animation implemented with social constructivist instruction on understanding of human reproductive system.

Fahyuni, E. F., \& Istikomah, I. (2016). Psikologi Belajar \& Mengajar (kunci sukses guru dalam interaksi edukatif).

Fauziyah, E. I., Praherdhiono, H., \& Ulfa, S. (2020). Efektivitas Penggunaan Video dengan Pengayaan Tokoh dan Animasi terhadap Pemahaman Konseptual Siswa. Jurnal Kajian Teknologi Pendidikan, 3(4), 448-455.

Febrianto, G. L., Sulton, H. P., \& Praherdiono, H. (2020). Pengembangan Media Video Pembelajaran untuk Pelatihan Instalasi Tenaga Listrik. Jurnal Kajian Teknologi Pendidikan, 3(2), 149-157.

Fitriani, A. A., Ulfa, S., \& Adi, E. P. (2020). Pengembangan Video Pembelajaran Animasi Sistem Pernapasan Manusia Sebagai Upaya Mendukung Kebijakan Belajar Di Rumah. Jurnal Kajian Teknologi Pendidikan, 3(3), 303-316.

González, G., \& Skultety, L. (2018). Teacher learning in a combined professional development intervention. Teaching and Teacher Education, 71, 341-354. https://doi.org/10.1016/j.tate.2018.02.003

Halili, S. H., Sulaiman, S., \& Abd Rashid, M. R. (2011). The Effectiveness of Learning Process Using Video Conferencing Technology. Jurnal Pendidikan Malaysia (Malaysian Journal of Education), 36(1), 55-65. 
Hamdu, G., \& Agustina, L. (2011). Pengaruh motivasi belajar siswa terhadap prestasi belajar IPA di sekolah dasar. Jurnal Penelitian Pendidikan, 12(1), 90-96.

Haythornthwaite, C., Kumar, P., Gruzd, A., Gilbert, S., Esteve del Valle, M., \& Paulin, D. (2018). Learning in the wild: Coding for learning and practice on Reddit. Learning, Media and Technology, 43(3), 219-235.

Iftene, A., \& Trandabăț, D. (2018). Enhancing the attractiveness of learning through Augmented Reality. Procedia Computer Science, 126, 166-175.

Imamah, N. (2012). Peningkatan hasil belajar IPA melalui pembelajaran kooperatif berbasis konstruktivisme dipadukan dengan video animasi materi sistem kehidupan tumbuhan. Jurnal Pendidikan IPA Indonesia, 1(1).

Kurniawan, D. C., Kuswandi, D., \& Husna, A. (2018). Pengembangan media video pembelajaran pada mata pelajaran IPA tentang sifat dan perubahan wujud benda kelas IV SDN Merjosari 5 Malang. JINOTEP (Jurnal Inovasi Dan Teknologi Pembelajaran): Kajian Dan Riset Dalam Teknologi Pembelajaran, 4(2), 119-125.

Lee, J., Han, J. H., Kim, M. S., Lee, H. S., Han, S. Y., Lee, S. J., \& Chae, H. (2020). Teaching Yin-Yang biopsychology using the animation, "Pororo the Little Penguin". European Journal of Integrative Medicine, 33, 101037. https://doi.org/10.1016/j.eujim.2019.101037

Lin, L., \& Li, M. (2018). Optimizing learning from animation: Examining the impact of biofeedback. Learning and Instruction, 55, 32-40. https://doi.org/10.1016/j.learninstruc.2018.02.005

Luhulima, D. A., Degeng, N. S., \& Ulfa, S. (2018). Pengembangan Video Pembelajaran Karakter Mengampuni Berbasis Animasi Untuk Anak Sekolah Minggu. JINOTEP (Jurnal Inovasi Dan Teknologi Pembelajaran): Kajian Dan Riset Dalam Teknologi Pembelajaran, 3(2), 110-120.

Luppy, F. M., Anwar, R. B., Linuhung, N., Agustina, R., \& Rahmawati, D. (2020). The Development of Animation-Based Learning Media Using Construct 2 On Logic Material. Matematika Dan Pembelajaran, 7(2), 13-21.

Manolev, J., Sullivan, A., \& Slee, R. (2019). The datafication of discipline: ClassDojo, surveillance and a performative classroom culture. Learning, Media and Technology, 44(1), $36-51$.

Massey, D., Byrne, J., Higgins, N., Weeks, B., Shuker, M.-A., Coyne, E., Mitchell, M., \& Johnston, A. N. B. (2017). Enhancing OSCE preparedness with video exemplars in undergraduate nursing students. A mixed method study. Nurse Education Today, 54, 56-61.

Montero Perez, M. (2020). Incidental vocabulary learning through viewing video: the role of vocabulary knowledge and working memory. Studies in Second Language Acquisition, 42(4), 749-773. Cambridge Core. https://doi.org/10.1017/S0272263119000706

Muhammad, M. (2017). Pengaruh motivasi dalam pembelajaran. Lantanida Journal, 4(2), 87-97.

Sadiman, A. (n.d.). Media Pendidikan, Pengertian, Pengembangan, dan Pemanfaatannya. Jakarta: PT. Raja Grafindo Persada.

Saputri, F. I. (2016). Pengaruh Gaya Belajar Visual, Auditori, dan Kinestetik Terhadap Prestasi Bejajar Siswa. Jurnal Prima Edukasia, 3(01), 25-36.

Satriesna, I. (2016). Aplikasi Pembelajaran Ilmu Grafika Berbasis Multimedia. 
Surahman, E., \& Surjono, H. D. (2017). Pengembangan adaptive mobile learning pada mata pelajaran biologi SMA sebagai upaya mendukung proses blended learning. Jurnal Inovasi Teknologi Pendidikan, 4(1), 26-37.

Tarchi, C., Zaccoletti, S., \& Mason, L. (2021). Learning from text, video, or subtitles: A comparative analysis. Computers \& Education, 160, 104034. https://doi.org/10.1016/j.compedu.2020.104034

Tu, J.-C., Liu, L.-X., \& Wu, K.-Y. (2018). Study on the learning effectiveness of Stanford design thinking in integrated design education. Sustainability, 10(8), 2649.

Wahyuni, Y. (2017). Identifikasi Gaya Belajar (Visual, Auditorial, Kinestetik) Mahasiswa Pendidikan Matematika Universitas Bung Hatta. JPPM (Jurnal Penelitian Dan Pembelajaran Matematika), 10(2).

Widiyasanti, M., \& Ayriza, Y. (2018). Pengembangan Media Video Animasi Untuk Meningkatkan Motivasi Belajar Dan Karakter Tanggung Jawab Siswa Kelas V. Jurnal Pendidikan Karakter, 8(1).

Yuhadiman, Y. (2014). LKP: Observasi Proses Cetak pada Divisi Packaging PT. Temprina Media Grafika.

Zhang, H., \& Pan, J. (2019). Casm: A deep-learning approach for identifying collective action events with text and image data from social media. Sociological Methodology, 49(1), 1-57. 